\title{
Concerning the importance of changes in hemorheological parameters caused by acid-base and blood gas alterations in experimental surgical models
}

\author{
Norbert Nemeth $^{\mathrm{a}, *}$, Iren Miko ${ }^{\mathrm{a}}$, Andrea Furka ${ }^{\mathrm{b}}$, Ferenc Kiss ${ }^{\mathrm{a}}$, Istvan Furka ${ }^{\mathrm{a}}$, Akos Koller ${ }^{\mathrm{c}}$ and \\ Maria Szilasi ${ }^{\mathrm{d}}$ \\ ${ }^{a}$ Department of Operative Techniques and Surgical Research, Institute of Surgery, Medical and Health \\ Science Center, University of Debrecen, Debrecen, Hungary \\ ${ }^{\mathrm{b}}$ Institute of Surgery, Medical and Health Science Center, University of Debrecen, Debrecen, Hungary \\ ${ }^{\mathrm{c}}$ Department of Pathophysiology and Gerontology, University of Pécs Medical School, Hungary \\ ${ }^{\mathrm{d}}$ Department of Pulmonology, Medical and Health Science Center, University of Debrecen, Debrecen, \\ Hungary
}

\begin{abstract}
Acid-base equilibrium and $\mathrm{pH}$ of blood have important clinical consequences in numerous diseases and pathophysiological conditions. The micro-rheological parameters of blood, such as red blood cell deformability and red blood cell aggregation are influenced by several metabolic factors, and provide information regarding inflammatory, septic and tissue or organ ischemia-reperfusion processes.

Despite the anticipated logical relation of the blood acid-base condition, blood gas parameters and $\mathrm{pH}$ to red blood cell deformability and aggregation, controversial data can be found in the literature. Furthermore, related to ischemia-reperfusion hemorheological studies little is known about this issue.

In this paper we aimed to thought-provokingly overview some aspect of acid-base changes, blood $\mathrm{pH}$ and hemorheological parameters, discussing certain results from ischemia-reperfusion experimental surgical models (local versus systemic changes), laboratory technical and experimental design protocols related to in vitro and in vivo studies.

Keywords: Acid-base changes, blood pH, micro-rheological parameters, red blood cell aggregation, red blood cell deformability.
\end{abstract}

\section{Introduction}

It is known that blood micro-rheological parameters, such as red blood cell deformability and red blood cell aggregation play an important role in determination of blood viscosity and resistance at various regions of the circulation in healthy and pathological conditions $[4,18,24,28,32,56]$.

Red blood cell deformability is determined by morphological properties of the cell (shape, volume, surface-to-volume ratio, cytoskeletal structure), own viscosity of the cell membrane, inner viscosity (hemoglobin content). Red blood cell aggregation -reversible coupling of erythrocytes at low shear

${ }^{*}$ Corresponding author: Norbert Nemeth, M.D., Ph.D., Department of Operative Techniques and Surgical Research, Institute of Surgery, Medical and Health Science Center, University of Debrecen, POB. 21, H-4012 Debrecen, Hungary. Tel.:+36 52416 915; E-mail: nemeth@med.unideb.hu. 


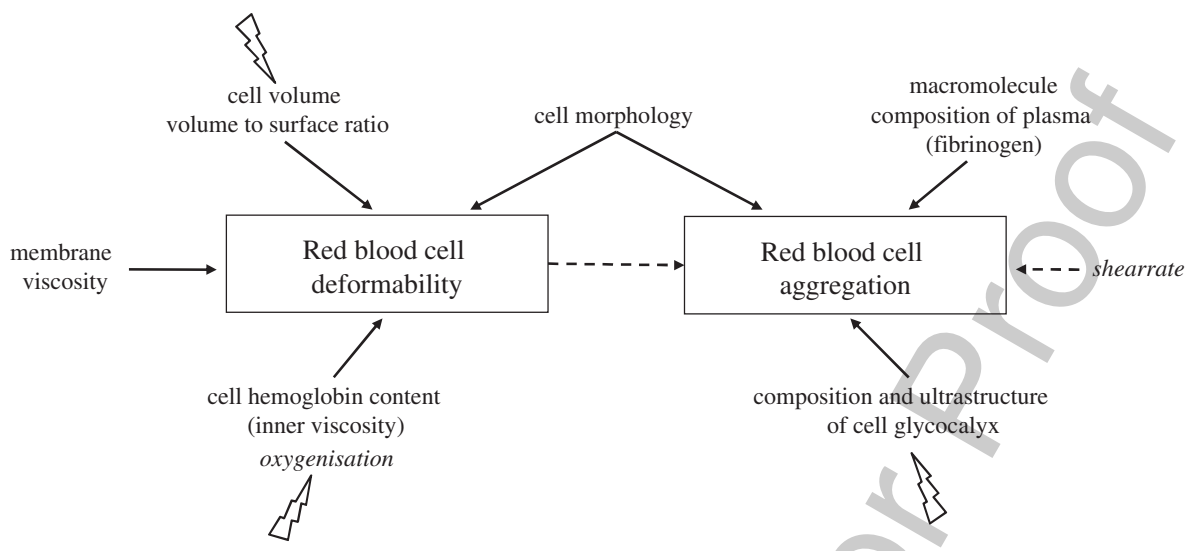

Fig. 1. Factors determining red blood cell deformability and red blood cell aggregation. Dashed lines reflect indirect relations between parameters. Thunder-like arrows show potential targets to be altered by changes in acid-base condition or blood gas partial pressure $\left(p \mathrm{O}_{2}, p \mathrm{CO}_{2}\right)$.

rate- is influenced by cellular (shape, deformability, membrane glycocalyx structure) and plasmatic factors (fibrinogen concentration and composition, micro-environmental conditions) $[4,5,9,15,16,31$, 52] (Fig. 1).

In surgical research ischemia-reperfusion $(I / R)$ is still an important topic because of its highly important clinical relevance and numerous unsolved questions concerning the time factor, local versus systemic changes, as well as prevention and therapeutic possibilities during and after surgery. Most of the experimental models are related to I/R injuries of solid organs and tissues, transplantation models or technical refinements of vessel anastomoses.

During I/R oxygen-derived free radical reactions, activated complements and leukocytes and related inflammatory processes, as well as local physical and metabolic changes may occur in blood, such as accumulation in lactate, decrease of $\mathrm{pH}$, changes in oxygenation (oxygenation-deoxygenation state) and fluid equilibrium, and micro-environmental alteration of blood osmolarity [20, 26, 33]. Red blood cell deformability and red blood cell aggregation are known to be affected by most of these alterations [e.g. 20, 25, 36-38]. However, the magnitude and reversibility of the micro-rheological changes are still unclear. Few number and controversial studies can be found in the literature in which red blood cell deformability and red blood cell aggregation have been investigated in parallel with acid-base, blood gas parameters and blood $\mathrm{pH}$. The lack of this kind of studies might be related to technical difficulties or poor experimental design, but on the other hand it also seems that this question has still not yet been clarified.

In this paper our aim was to briefly and thought-provokingly overview some aspects and concerns on the alterations of acid-base and hemorheological parameters, discussing some results from ischemiareperfusion experimental surgical models, laboratory technical, measuremental issues and experimental design.

\section{Data on acid-base changes and alterations in hemorheological variables}

\subsection{Physiological conditions}

Although several in vitro studies demonstrated the effect of $\mathrm{pH}[11,15,23,27,55], p \mathrm{O}_{2}[11,43,51]$ and lactate concentration [17, 30, 41] on red blood cell properties, the in vivo studies (using ex vivo 
samples) often show controversial data. The most complex literature data on acid-base, lactate and $\mathrm{pH}$ changes is being related to hemorheology have been originated from studies in exercise physiology and pathophysiology [10].

Many authors concluded that increased lactate level has impairing effect on red blood cell deformability and aggregation $[8,9,12-14,46,50]$. However physical exercise itself shows wide individual range and differs among well-trained and not trained volunteers $[13,45]$. In well-trained athletes red blood cell aggregation could not be modified by exercise (cyclo-ergometer) or in vitro incubation with sodium-lactate solution $(2,4$ and $10 \mathrm{mM}$ in HEPES; osmolarity $=210 \mathrm{mOsmol} / \mathrm{kg} ; \mathrm{pH}=7.4)$ [13]. Probably due to the altered rate of lactate influx into red blood cells [45], in untrained subjects erythrocyte rigidity coefficient (Tk) -an indirect, estimating parameter for red blood cell deformability-increased significantly when incubated in sodium-lactate of $4 \mathrm{mM}$ compared to $2 \mathrm{mM}$. In well-trained athletes Tk slightly decreased [13]. Also Smith and co-workers reported exercise-induced increase of lactate level, red blood cell osmotic fragility and mean cell volume. These impairments could be simulated in vitro by putting $15 \mathrm{mM}$ l-lactic acid (dissociating into lactate anion and $\mathrm{H}^{+}$) into the samples [46].

Senturk and co-workers reported that contrary to trained subjects in sedentary volunteers exercise induced significant impairment in red blood cell deformability. Interestingly, the exercise-induced rise in oxidative stress markers (TBARS, carbonyl derivative) were almost identical in those groups as well as the lactate level (sedentary: $9.4 \pm 0.7 \mathrm{mmol} / \mathrm{l}$; trained: $10.2 \pm 1.2 \mathrm{mmol} / \mathrm{l}$ ) [44].

Animal experiments have also demonstrated that strenuous exercise significantly influences microrheological parameters. Yalcin and co-workers described that 60-minute swimming exercise of trained (gradually built up protocol of 60-minute swimming 5 days per week for 6 weeks) rats did not cause enhancement of red blood cell aggregation nor definitive impairment of red blood cell aggregation compared to untrained animals $[2,54]$.

In normal metabolism the l-lactate is produced from pyruvate by the lactate dehydrogenase (LDH) enzyme. The main pathways of removal of lactate are oxidation to pyruvate or conversion to glucose (Cori-cycle). Lactate anion enters into the red blood cells and independently from the $\mathrm{pH}\left(\mathrm{H}^{+}\right)$may cause impairment in erythrocyte rheological properties [12, 30, 41]. About $90 \%$ of the total lactate uptake is linked to the red blood cell monocarboxylate transporter (lactate $/ \mathrm{H}^{+}$co-transporter) $[14,17]$.

However exercise-induced changes in red blood cell micro-rheological properties are controversial: red blood cell aggregation has been reported exercise induced increase or decrease, or even without change as well $[14,50]$. From the exercise physiology studies we could learn many data about the effects of lactate concentration, blood $\mathrm{pH}$, acid-base parameters on red blood cell deformability and aggregation tested in systemic blood samples. Changes in lactate level, $\mathrm{pH}$ are also important in ischemiareperfusion condition, and so the I/R-related hemorheological research; and not only in systemic, but in local circulatory aspects, too.

\subsection{Ischemia-reperfusion studies}

The complex pathophysiological processes during ischemia and reperfusion have been widely investigated [e.g. 20,33]. Several components of the ischemia-reperfusion is responsible for impaired red blood cell deformability or enhanced red blood cell aggregation. These include direct effects oxygen-derived free radical reactions and activated neutrophils, endothelial interactions, nitric-oxide-related processes, mechanical trauma as well as micro-environmental changes (e.g. pH, osmolarity) $[2,20,25,26,33$, 36, 38].

After ischemia the systemic consequences are partly originated from the washout of locally accumulated metabolites: production of lactate and $\mathrm{H}^{+}$and consequent change of acid-base balance toward acidosis, 
increased potassium concentration [33]. These changes may cause further local tissue and endothelial damage, contributing to the characteristic microcirculatory disturbances, such as the "no-reflow" phenomenon [6,39]. Systemic activation of complement system and polymorphonuclear leukocytes and the release of intracellular myoglobin (in case of skeletal muscle ischemia) may lead to life-threatening organ damage (renal-, pulmonary-, cardiac failure, MOF) [33].

Numerous ischemia-reperfusion models have been studied by us. In these models one of the most important questions was the local versus systemic relation of hemorheological changes related to I/R injury of intestines [7], liver [19], hind limb [36, 38, 48] and muscle flap [49]. According to the available instrumental possibilities, and depending on the available-requested blood sample volume, we could test acid-base balance parameters, blood $\mathrm{pH}$, metabolites. In a rat model of 2-hour hind limb ischemia arteriovenous values of $\mathrm{pH}, p \mathrm{O}_{2}, p \mathrm{CO}_{2}$ and hematocrit have been monitored in the first hour of reperfusion, showing significant decrease in venous blood $\mathrm{pH}$ compared to arterial and control values [48]. A canine hind limb ischemia-reperfusion model demonstrated serious hemorheological impairment of the excluded blood in the ischemic extremity [38]. Also cerebral hypoperfusion model in a porcine study clearly showed that lactate accumulation in the superior sagittal sinus causes significant impairment of red blood cell filterability [37].

During ischemia, while the blood is in stasis in the excluded tissue region, organ or extremity, local metabolic and physical changes may directly influence the blood rheological parameters. Lactate accumulation in blood and tissues may influence blood rheological properties: decreasing red blood cell deformability and increasing blood viscosity $[41,50]$.

Morphologically red blood cells may show definitive variety of cell shapes depending on the microenvironmental conditions. It is known as stomatocyte-discocyte-echinocyte sequence [5]. Anionic amphipaths, alkalic $\mathrm{pH}$, ATP depletion induce echinocytes, which forms are initially reversible, but may turn into sphero-echinocyte irreversibly. Cationic amphipaths, acidic $\mathrm{pH}$ induce concave stomatocytes, which may irreversibly become sphero-stomatocyte [5, 29]. It is known that both echinocyte and stomatocyte forms have impaired deformability and disturbed aggregation. For aggregation the biconcave shape is ideal, echinocytes do not aggregate well $[35,40]$.

Therefore, determining acid-base parameters and blood $\mathrm{pH}$ has importance to evaluate red cell properties. However, several questions raise. What is the range of red blood cell deformability and aggregation changes and where is the border of reversibility-irreversibility in this sequence? How could it be determined technically?

\section{Experimental and technical considerations}

Results obtained from ex vivo samples and the original in vivo conditions can be definitely altered to each other. In many hemorheological methods blood samples are processed to produce cell suspension in various buffers and/or macromolecule solutions [3,21], taking out of the original sampling tube into other tubes, having contact with laboratory air, changing in temperature, eliciting trauma of the samples (e.g. centrifugation, suspension preparations), the problem of sample storage (in vitro aging) [3, 35].

In experimental surgical models when investigating hemorheological parameters it is important to consider the inter-species differences $[34,53]$ and the potential discrepancy between the quantity of available and required blood sample volume, in addition to many questions of experimental design.

Concerning the local versus systemic hemorheological changes and their investigation, the blood sampling site may vary according to the experimental protocol. Therefore, data on arterio-venous differences 
are important [22, 47]. Sample handling and sample oxygenation level may also influence the results, when the aim is to analyze hemorheological variables together with blood $\mathrm{pH}$ and gas parameters $\left(\mathrm{pO}_{2}\right.$, $\left.\mathrm{pCO}_{2}\right)[3,51]$.

\section{Effects of oxygenation-deoxygenation and $\mathrm{pH}$ on rheological parameters of erythrocytes}

To understand the local versus systemic changes of red blood cell deformability and aggregation, the cell oxygenation, blood $\mathrm{pH}$ and lactate concentration have importance.

Concerning oxygenation-deoxygenation, $\mathrm{pH}$ dependent red blood cell morphology and aggregation behavior, Cicha and co-workers reported very interesting data, suggesting that the magnitude of the changes was dependent on the method of deoxygenation (i.e. 95\% $\mathrm{N}_{2}-5 \% \mathrm{CO}_{2}$ or $\mathrm{N}_{2}$ alone) [11]. Oxygenated red blood cell $\left(95 \% \mathrm{O}_{2}-5 \% \mathrm{CO}_{2}\right)$ showed significantly higher aggregation (increased rouleaux formation rate) than the cells incubated with the $\mathrm{N}_{2} / \mathrm{CO}_{2}$ gas mixture. If the cells were incubated with air $\left(\mathrm{pO}_{2}=155-160 \mathrm{mmHg}\right)$ the aggregation increased, but not as much as with deoxygenation by incubation in $\mathrm{N}_{2}$. The rouleaux formation rate positively correlated with increasing $\mathrm{pH}$. The lowest data were found by $\mathrm{O}_{2} / \mathrm{N}_{2}$ and $\mathrm{N}_{2} / \mathrm{CO}_{2}$ incubation (mean $\mathrm{pH}=7.54$ and 7.5 , respectively), the highest in case of air and $\mathrm{N}_{2}$ incubation (man $\mathrm{pH}=8.23$ and 8.41, respectively). Similar correlation was found with mean corpuscular hemoglobin concentration; with increasing $\mathrm{pH}$ the MCHC increased with flattened cell forms (increased surface-to-volume ratio), showing enhanced red blood cell aggregation [11].

The physiological blood $\mathrm{pH}$ has an accurately and well regulated range of 7.35-7.45 with well known respiratory and metabolic compensatory mechanism. Local $\mathrm{pH}$ in tissues, at the microcirculatory level is influenced by several factors (e.g. Donnan membrane equilibrium intracellular buffering, ion exchange) and may vary in wider range $[11,42]$. However, the $\mathrm{pH}$ range used in the study by Cicha and co-workers is much more over the physiologically tolerable range.

Uyuklu and co-workers used a closer $\mathrm{pH}$ range for investigation the effect of oxygenation or deoxygenation on red blood cell aggregation and deformability [51]. Oxygenated samples (mean $p \mathrm{O}_{2}=142 \mathrm{mmHg}$; $\mathrm{pH}=7.8)$ had significantly lower aggregation index and better red blood cell deformability versus deoxygenated samples (mean $\mathrm{pO}_{2}=28.6 \mathrm{mmHg} ; \mathrm{pH}=7.74$ ). The native, control blood samples (mean $p \mathrm{O}_{2}=42.4 \mathrm{mmHg} ; \mathrm{pH}=7.4$ ) showed aggregation and deformability values between the two incubated samples' data [51]. These data are very useful for standardization of laboratory measurement techniques, sampling and handling conditions [3].

\section{Concluding thoughts}

It is seen from the literature that the magnitude of changes in red blood cell deformability and aggregation and the range or border of reversibility-irreversibility are still controversial, being technically very difficult to test objectively. Therefore the accurate design of experiment, standardization of methods (sampling site and method, sample preparation and handling, measurement conditions and if necessary instrumental adaptations) all have great importance to have enough valuable and objective data to clarify better the relation of acid-base and blood $\mathrm{pH}$ changes to blood rheological parameters.

We believe that one of the most important factors is the blood sampling-handling to obtain valuable data in ex vivo samples [3, 35]. In ischemia-reperfusion models the comparison of local versus systemic changes has important clinical relevance. However, when evaluating results the relation of in vivo hemorheology with the ex vivo samples means always a limit of extrapolation [1]. 
Both in small and large animal ischemia-reperfusion models -depending on the available/requested blood sample volume- blood gas, $\mathrm{pH}$, lactate level determinations are necessary. According to the experimental design local and systemic blood samples are also needed to be tested. Hopefully, in the future there will be minimally invasive devices/sensors that are capable to test in vivo local and systemic hemorheological parameters in their complexity. Till that these parameters can be tested separately and only on $e x$ vivo samples.

\section{Acknowledgments}

Scientific Grants: The Hungarian Scientific Research Fund OTKA K-67779 and OTKA F-68323; Janos Bolyai Research Scholarship of the Hungarian Academy of Sciences (Norbert Nemeth).

The authors comply with the Ethical Guidelines for Publication in Clinical Hemorheology and Microcirculation as published on the IOS Press website and in Volume 44, 2010, pp. 1-2 of this journal.

\section{References}

[1] O.K. Baskurt, In vivo correlates of altered blood rheology, Biorheology 45 (2008), 629-638.

[2] O.K. Baskurt, Mechanisms of blood rheology alterations, in: Handbook of Hemorheology and Hemodynamics, O.K. Baskurt, M.R. Hardeman, M.W. Rampling and H.J. Meiselman, eds. IOS Press Amsterdam, The Netherlands 2007 pp. 170-190.

[3] O.K. Baskurt, M. Boynard, G.C. Cokelet, P. Connes, B.M. Cooke, S. Forconi, M.R. Hardeman, F. Jung, F. Liao, H.J. Meiselman, G. Nash, N. Nemeth, B. Neu, B. Sandhagen, S. Shin, G. Thurston and J.L. Wautier, International expert panel for standardization of hemorheological methods, New guidelines for hemorheological laboratory techniques, Clin Hemorheol Microcirc 42 (2009), 75-97.

[4] O.K. Baskurt and H.J. Meiselman, Blood rheology and hemodynamics, Semin Thromb Hemostas 29 (2003), 435-450.

[5] M. Bessis, Living blood cells and their ultrastructure, Springer-Verlag, Berlin, New York, 1973.

[6] J. Bhavsar and R.S. Rosenson, Adenosine transport, erythrocyte deformability and microvascular dysfunction: An unrecognized potential role for dipyridamole therapy, Clin Hemorheol Microcirc 44 (2010), 193-205.

[7] E. Brath, N. Nemeth, F. Kiss, E. Sajtos, T. Hever, L. Matyas, L. Toth, I. Miko and I. Furka, Changes of local and systemic hemorheological properties in intestinal ischemia-reperfusion injury in the rat model, Microsurgery 30 (2010), 321-326.

[8] J.F. Brun, Exercise hemorheology as a three acts play with metabolic actors: Is it of clinical relevance? Clin Hemorheol Microcirc 26 (2002), 155-174.

[9] J.F. Brun, Hormones, metabolism and body composition as major determinants of blood rheology: Potential pathophysiological meaning, Clin Hemorheol Microcirc 26 (2002), 63-79.

[10] J.F. Brun, E. Varlet-Marie, P. Connes and I. Aloulou, Hemorheological alterations related to training and overtraining, Biorheology 47 (2010), 95-115.

[11] I. Cicha, Y. Suzuki, N. Tateishi and N. Maeda, Changes of RBC aggregation in oxygenation-deoxygenation: $\mathrm{pH}$ dependency and cell morphology, Am J Physiol - Heart Circ Physiol 284 (2003), H2335-H2342.

[12] P. Connes, D. Bouix, G. Py, C. Prefaut, J. Mercier, J.F. Brun and C. Caillaud, Opposite effects of in vitro lactate on erythrocyte deformability in athletes and untrained subjects, Clin Hemorheol Microcirc 31 (2004), 311-318.

[13] P. Connes, C. Caillaud, G. Py, J. Mercier, O. Hue and J.F. Brun, Maximal exercise and lactate do not change red blood cell aggregation in well trained athletes, Clin Hemorheol Microcirc 36 (2007), 319-326.

[14] P. Connes, J. Tripette, M. Mukisi-Mukaza, O.K. Baskurt, K. Toth, H.J. Meiselman, O. Hue and S. Antoine-Jonville, Relationships between hemodynamic, hemorheological and metabolic responses during exercise, Biorheology 46 (2009), 133-143.

[15] E.D. Crandall, A.M. Critz, A.S. Osher, D.J. Keljo and R.E. Forster, Influence of pH on elastic deformability of human erythrocyte-membrane, Am J Physiol 235 (1978), C269-C278.

[16] S. de Oliveira and C. Saldanha, An overview about erythrocyte membrane, Clin Hemorheol Microcirc 44 (2010), $63-74$. 
[17] B. Deuticke, E. Beyer and B. Forst, Discrimination of three parallel pathways of lactate transport in human erythrocyte membrane by inhibitors and kinetic properties, Biochim Biophys Acta 684 (1982), 96-110.

[18] K. Ergun-Cagli, E. Ileri-Gurel, O. Ozeke, N. Seringec, A. Yalcinkaya, S. Kocabeyoglu, F.N. Basar, N. Sen, K. Cagli and N. Dikmenoglu, Blood viscosity changes in slow coronary flow patients, Clin Hemorheol Microcirc 47 (2011), $27-35$.

[19] A. Furka, N. Nemeth, A. Gulyas, E. Brath, K. Peto, E.I. Takacs, I. Furka, P. Sapy and I. Miko, Hemorheological changes caused by intermittent Pringle (Baron) maneuver in experimental beagle canine model, Clin Hemorheol Microcirc 40 (2008), 177-189.

[20] T. Gori, M. Lisi and S. Forconi, Ischemia and reperfusion: The endothelial perspective. A radical review, Clin Hemorheol Microcirc 35 (2006), 31-34.

[21] M.R. Hardeman, P.T. Goedhart and S. Shin, Methods in hemorheology, in: Handbook of Hemorheology and Hemodynamics, O.K. Baskurt, M.R. Hardeman, M.W. Rampling and H.J. Meiselman, eds., IOS Press, Amsterdam, The Netherlands, 2007, pp. 242-266.

[22] T. Hever, F. Kiss, E. Sajtos, L. Matyas and N. Nemeth, Are there arterio-venous differences of blood micro-rheological variables in laboratory rats? Korea-Aust Rheol J 22 (2010), 59-64.

[23] R.M. Johnson, pH effects on red blood cell deformability, Blood Cells 11 (1985), 317-321.

[24] F. Jung, C. Mrowietz, B. Hiebl, R.P. Franke, G. Pindur and R. Sternitzky, Influence of rheological parameters on the velocity of erythrocytes passing nailfold capillaries in humans, Clin Hemorheol Microcirc 48 (2011), 129-139.

[25] E. Kayar, F. Mat, H.J. Meiselman and O.K. Baskurt, Red blood cell rheological alterations in a rat model of ischemiareperfusion injury, Biorheology 38 (2001), 405-414.

[26] R. Koppensteiner, Blood rheology in emergency medicine, Semin Thromb Hemost 22 (1996), 89-91.

[27] D. Kuzman, T. Znidarcic, M. Gros, S. Vrhovec, S. Svetina and B. Zeks, Effects of pH on red blood cell deformability, Pflugers Arch - Eur J Physiol 440(Suppl 5) (2000), R193-R194.

[28] H.C. Kwaan, Role of plasma proteins in whole blood viscosity: A brief clinical review, Clin Hemorheol Microcirc 44 (2010), 167-176.

[29] G.H.W. Lim, M. Wortis and R. Mukhopadhyay, Stomatocyte-discocyte-echinocyte sequence of the human red blood cell: Evidence for the bilayer-couple hypothesis from membrane mechanics, PNAS 99 (2002), 16766-16769.

[30] V. Lipovac, M. Gavella, Z. Turk and Z. Skrabalo, Influence of lactate on the insulin action on red blood cell filterability, Clin Hemorheol 5 (1985), 421-428.

[31] H.J. Meiselman, Morphological determinants of red blood cell deformability, Scand J Clin Lab Invest 41(Suppl 156) (1981), 27-34.

[32] H.J. Mutsaerts, M. Out, P.T. Goedhart, C. Ince, M.R. Hardeman, J.A. Romijn, T.J. Rabelink, J.H. Reiber and F.M. Box, Improved viscosity modeling in patients with type 2 diabetes mellitus by accounting for enhanced red blood cell aggregation tendency, Clin Hemorheol Microcirc 44 (2010), 303-313.

[33] J. Nanobashvili, C. Neumayer, A. Fuegl, E. Sporn, M. Prager, P. Polterauer, T. Malinski and I. Huk, Ischaemia/reperfusion injury of skeletal muscle: Mechanism, morphology, treatment strategies, and clinical applications, Eur Surg 34 (2002), 83-89.

[34] N. Nemeth, T. Alexy, A. Furka, O.K. Baskurt, H.J. Meiselman, I. Furka and I. Miko, Inter-species differences in hematocrit to blood viscosity ratio, Biorheology 46 (2009), 155-165.

[35] N. Nemeth, O.K. Baskurt, H.J. Meiselman, F. Kiss, M. Uyuklu, T. Hever, E. Sajtos, P. Kenyeres, K. Toth, I. Furka and I. Miko, Storage of laboratory animal blood samples causes hemorheological alterations: Inter-species differences and the effects of duration and temperature, Korea-Aust Rheol J 21 (2009), 127-133.

[36] N. Nemeth, T. Lesznyak, M. Szokoly, I. Furka and I. Miko, Allopurinol prevents erythrocyte deformability impairing but not the hematological alterations after limb ischemia-reperfusion in rats, J Invest Surg 19 (2006), 47-56.

[37] N. Nemeth, J. Soukup, M. Menzel, D. Henze, T. Clausen, A. Rieger, C. Holz, A. Scharf, F. Hanisch, I. Furka and I. Miko, Cerebral hyper- and hypoperfusion and its local and systemic hemorheological effects in a porcine model, Clin Hemorheol Microcirc 35 (2006), 59-65.

[38] N. Nemeth, M. Szokoly, G. Acs, E. Brath, T. Lesznyak, I. Furka and I. Miko, Systemic and regional hemorheological consequences of warm and cold hind limb ischemia-reperfusion in a canine model, Clin Hemorheol Microcirc 30 (2004), $133-145$.

[39] T. Reffelmann and R.A. Kloner, The "no-reflow" phenomenon: Basic science and clinical correlates, Heart 87 (2002), $162-168$.

[40] W.H. Reinhart and S. Chien, Red cell rheology in stomatocyte-echinocyte transformation: Roles of cell geometry and cell shape, Blood 67 (1980), 1110-1118. 
[41] W.H. Reinhart, R. Gaudenz and R. Walter, Acidosis induced by lactate, pyruvate, or $\mathrm{HCl}$ increases blood viscosity, Crit Care 17 (2002), 38-42.

[42] A. Ross and W.F. Boron, Intracellular pH, Physiol Rev 61 (1981), 296-434.

[43] P. Rusch, T. Hermann, A. Geyssant, C. Vasselon and J.C. Healy, Influence of oxygen tensions, intracellular enzymes and hematological factors on RBC filterability, Biorheology 18 (1981), 493-508.

[44] U.K. Senturk, F. Gunduz, O. Kuru, G. Kocer, Y.G. Ozkaya, A. Yesilkaya, M. Bor-Kucukatay, M. Uyuklu, O. Yalcin and O.K. Baskurt, Exercise-induced oxidative stress leads hemolysis in sedentary but not trained humans, J Appl Physiol 99 (2005), 1434-1441.

[45] M.S. Skelton, D.E. Kremer, E.W. Smith and L.B. Gladden, Lactate influx into red blood cells from trained and untrained human subject, Med Sci Sports Exerc 30 (1998), 536-542.

[46] J.A. Smith, R.D. Telford, M. Kolbuch-Braddon and M.J. Weidemann, Lactate/H+ uptake by red blood cells during exercise alters their physical properties, Eur J Appl Physiol Occup Physiol 75 (1997), 54-61.

[47] K.H. Son, C.H. Lim, E.J. Song, K. Sun, H.S. Son and S.H. Lee, Inter-species hemorheologic differences in arterial and venous blood, Clin Hemorheol Microcirc 44 (2010), 27-33.

[48] M. Szokoly, N. Nemeth, J. Hamar, I. Furka and I. Miko, Early systemic effects of hind limb ischemia-reperfusion on hemodynamics and acid-base balance in the rat, Microsurgery 26 (2006), 585-589.

[49] R. Tamas, N. Nemeth, E. Brath, M. Sasvari, C. Nyakas, B. Debreczeni, I. Miko and I. Furka, Hemorheological, morphological and oxidative changes during ischemia-reperfusion of latissimus dorsi muscle flaps in a canine model, Microsurgery 30 (2010), 282-288.

[50] K. Toth, G. Kesmarky and T. Alexy, Clinical significance of hemorheological alterations, in: Handbook of Hemorheology and Hemodynamics, O.K. Baskurt, M.R. Hardeman, M.W. Rampling and H.J Meiselman, eds., IOS Press, Amsterdam, The Netherlands, 2007, pp. 392-432.

[51] M. Uyuklu, H.J. Meiselman and O.K. Baskurt, Effect of hemoglobin oxygenation level on red blood cell deformability and aggregation parameters, Clin Hemorheol Microcirc 41 (2009), 179-188.

[52] R.I. Weed, P.L. La Celle and E.W. Merrill, Metabolic dependence of red blood cell deformability, J Clin Invest 48 (1969), 795-809.

[53] U. Windberger, O.K. Baskurt Comparative hemorheology, in; Handbook of Hemorheology and Hemodynamics, O.K. Baskurt, M.R. Hardeman, M.W. Rampling and H.J. Meiselman, eds., IOS Press, Amsterdam The Netherlands 2007 pp. 267-285.

[54] O. Yalcin, M. Bor-Kucukatay, U.K. Senturk and O.K. Baskurt, Effects of swimming exercise on red blood rheology in trained and untrained rats, J Appl Physiol 88 (2000), 2074-2080.

[55] C.C. Yao, Z.G. Zha, Effects of incubation $\mathrm{pH}$ on the membrane deformation of a single living human red blood cell, Curr Appl Physics 7(Suppl 1) (2007), e11-e14.

[56] F. Yilmaz, M.Y. Gundogdu, A critical review on blood flow in large arteries; relevance to blood rheology, viscosity models, and physiologic conditions, Korea-Aust Rheol J 20 (2008), 197-211. 